\title{
A Short History of the Use of Plants as Medicines from Ancient Times
}

\author{
Hani Mutlak A. Hassan*
}

Abstract: A concise historical overview on the use of plants for medical treatments from ancient times is discussed.

Keywords: History of science · Plants · Traditional medicine

\section{Introduction}

There is real evidence that humans have relied on Nature for medicines for thousands of years and plants or plant extracts have formed the basis of traditional medicine. Traditional medicine is still practiced nowadays in different parts of the world and was the origin of medical treatments. Even though the use of plants as medicinal drugs is an ancient science which dates back several millennia, many of the most significant drug advances have been made within the last century. It would be reasonable to state that man's encounter with sickness has prompted the rubbing or chewing of seeds, leaves, and other parts of plants in order to alleviate illness. Historical trial and error practices on different plants resulted in some plants being helpful against diseases and, gradually over time, specific plants were discovered that treat certain diseases.

\section{History of the Use of Plants as Medicines}

One of the oldest records and considered the oldest written evidence of medicinal plants' usage goes back to about 5000 years ago and was written on Sumerian clay slabs containing a dozen recipes for

${ }^{*}$ Correspondence: Dr. H. M. A. Hassan King Fahd Medical Research Center King Abdulaziz University

P.O. Box 80216, Jeddah 21589, KSA

E-mail: hmahassan@kau.edu.sa drug preparations of over 200 different plants. ${ }^{[1]}$ Other records, which date back to around $2600 \mathrm{BC}$, came from ancient Mesopotamia and were recorded on clay tablets in cuneiform script. [2] There is evidence that medicinal plants have been used in early civilizations as demonstrated by the Chinese emperor Shen Nung ( $c a .2500$ BC) who compiled descriptions of over 300 medicinal herbs and the Chinese materia medica has a long impressive history. ${ }^{[3]}$ Many of those herbs have been reported as medicines in different parts of the world such as ancient Egypt, Mesopotamia, and Europe. Opium is one of mankind's oldest effective drugs and was used several millennia ago.

The Assyrians, Babylonians, and Sumerians recorded herbal remedies in cuneiform inscriptions on numerous clay tablets and the Code of Hammurabi ${ }^{[4]}\left(18^{\text {th }}\right.$ century BC) contains many herbal medicines. The Egyptians recorded their medicinal knowledge in tomb illustrations and on papyrus dating from the Old Kingdom of Egypt. The 'Ebers Papyrus' (ca. 1550) was the most important of these recordings and contains over 600 prescription drugs of various plant species. ${ }^{[5]}$ European medicine is thought to have initiated with Hippocrates (460-377 BC) who compiled over 200 medicinal plants which were classified by physiological action and he is considered the 'father of medicine'. ${ }^{[6]}$ Celsus (25 BC$50 \mathrm{AD})$, who was a famous medical writer, mentioned about 250 medicinal plants in his 'De re medica' book. [7] Dioscorides, who was a Greek military physician and considered the 'father of pharmacognosy', recorded the use of medicinal plants and wrote De Materia Medica in ca. 77 AD, which was used as a reference in Europe for more than a millennium and translated into several languages. ${ }^{[8]}$ It included over 900 drugs and most of them were of plant origin. Galen (130-200 AD), who was a renowned Greek physician and pharmacist, influenced the development of various scientific disciplines and documented the use of plants as medicines. ${ }^{[9]}$
Native Americans used plants as medicines for centuries and some anticancer drugs that are currently available to treat various cancers are derived from plants in North America such as the Pacific yew tree (Taxus brevifolia) from which the anticancer drug paclitaxel $\left(\right.$ Taxol $\left.^{\circledR}, \mathbf{1}\right)$ is derived (Fig. 1). ${ }^{[10]}$ African traditional medicine has also been practiced for many centuries and it has diverse medical treatments for different diseases but it was poorly recorded. ${ }^{[11]}$

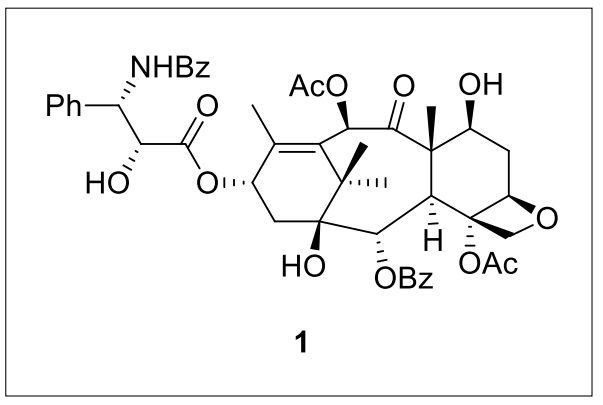

Fig. 1. Structure of paclitaxel $\left(\right.$ Taxol $^{\circledR}$, derived from Taxus brevifolia).

In the $17^{\text {th }}$ century, one of the best herbal remedies was introduced into Europe; the use of the bark of the Cinchona tree which became a popular medicine to treat malaria. Its active ingredient quinine (2) was isolated two centuries later (1820). In the $18^{\text {th }}$ century, the foxglove plant was used by Withering for treating dropsy ${ }^{[12]}$ and the active ingredient (digoxin) is currently being used for treating various heart conditions. The first 'pure' drugs became available during the $19^{\text {th }}$ century. The alkaloids quinine $(\mathbf{2}, 1820)$, morphine $(\mathbf{3}, 1806)$, and ephedrine $(4,1887)$ were extracted from plants and chemists later on were able to disclose the chemical synthesis of these important alkaloids (Fig. 2).

A considerable number of drugs appeared in the second half of the $20^{\text {th }}$ century that can treat diverse diseases as a result of the advancement in pharmaceutical science and the establishment of pharmaceutical companies. Although both synthetic 


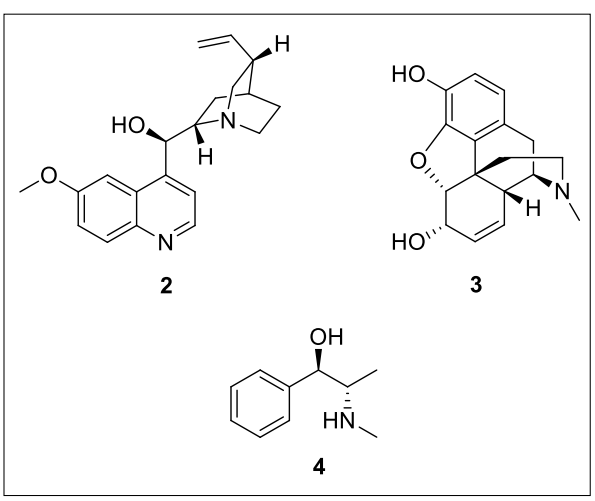

Fig. 2. Structures of quinine 2, morphine 3, and ephedrine 4.

and natural product-based drugs are currently used in curing diseases, numerous drugs in clinical use today are based on plant-derived natural products or their analogues.

\section{Conclusions}

Given the above historical account of medicinal plants use as medicines for thousands of years and the ongoing discoveries of new drugs from Nature, it is with no doubt that plants will remain a rich source of medicine and will certainly continue to supply mankind with novel remedies.

\section{Acknowledgements}

The author would like to thank King Abdulaziz University and King Abdulaziz City of Science and Technology (KACST) for support.

Received: May 14, 2015
[1] J. Sumner, 'The Natural History of Medicinal Plants', Timber Press, London, 2000.

[2] J. Scurlock, 'Sourcebook for Ancient Mesopotamian Medicine', SBL Press, Atlanta, 2014.

[3] Y. P. Zhu, 'Chinese Materia Medica: Chemistry, Pharmacology and Applications', Harwood Academic Publishers, Amsterdam, 1998.

[4] H. E. Sigerist, 'A History of Medicine', Vol. 1, Oxford University Press, New York, 1955.

[5] R. A. Le Strange, 'A History of Herbal Plants', Arco Publishing Company Inc., New York, 1977.

[6] A. Castiglioni, 'A History of Medicine', Jason Aronson Inc. Publishers, New York, 1985.

[7] A. C. Celsus, 'De Medicina', Harvard University Press, Cambridge MA, 1948.

[8] J. M. Riddle, 'Dioscorides on Pharmacy and Medicine', University of Texas Press, Austin, 1985.

[9] 'Alkaloids: Biochemistry, Ecology, and Medicinal Applications', Eds. M. F. Roberts, M. Wink, Plenum Press, New York, 1998.

[10] K. C. Nicolaou, E. J. Sorensen, N. Winssinger, J. Chem. Educ. 1998, 75, 1225.

[11] R. Vossen, K. Keuthmann, 'Contemporary Studies on Khoisan 1', Helmut Buske Verlag, Hamburg, 1986.

[12] W. Withering, 'An Account of the Foxglove and Some of Its Medical Uses', Birmingham: M. Swinney, 1785. 